\title{
Evaluation of spiritual health level and its related factors in the students of Sanandaj Universities, 2015
}

\author{
Mahnaz Sayyadi ${ }^{1}$, Sirvan Sayyad ${ }^{2}$, Ahmad Vahabi $^{3}$, Boshra Vahabi ${ }^{1}$, Bijan Noori ${ }^{4}$, Mona \\ Amani $^{1}$
}

1-Student Research Committee, Kurd istan University of Medical Sciences, Sanandaj, Iran. ORCID: 0000-00034496-0970

2-Student Research Co mmittee, Kermanshah University of Medical Sciences, Kermanshah, Iran. ORCID: 00000002-9316-886X

3-Assistant Professor, Department of Medical Laboratory Sciences, Faculty of Paramedical Sciences, Kurdistan University of Medical Sciences, Sanandaj, Iran (Corresponding Author ). ORCID: 0000-0003-4301-179X

E-mail: vahabiahmad@g mail.com

4Assistant Professor, Social Determinants of Health Research Center, Research Institute for Health Develop ment, Kurd istan University of Medical Sciences, Sanandaj, Iran . ORCID: 0000-0003-0064-0094

Recei ved: 01/09/2018

Accepted: 28/12/2018

\begin{abstract}
Introduction: Spirituality is the most important aspect of human existentialism. This dimension is considered as a strong force in the center of life for more than one-third of the people worldwide. Spirituality is linked to health, a sense of goodness and recovery, and a factor in the continuation of life, finding its meaning and purpose.

Aim: This study aimed to determine spiritual health level and its related factors in the students of Sanandaj universities in 2015.

Method: The present study was a cross-sectional. The study population, were students of Kurdistan University, Islamic Azad University of Sanandaj and Kurdistan University of Medical Sciences. Five hundred persons of them were selected and studied using One-stage cluster sampling method. A two-part questionnaire including demographic characteristics and 20 questions about spiritual health was used. The data were analyzed using SPSS 20.

Results: The mean score of the belief system, intellectual, moral and life style of spiritual health were $25.78 \pm 3.95,25.54 \pm 4.37,22.97 \pm 4.65$ and $23.04 \pm 4.75$, respectively. The mean overall score of spiritual health was $96.33 \pm 14.92$. The score was at the high level of health. There was a statistically significant difference between degrees $(p<0.001)$, university $(\mathrm{p}<0.001)$, group study $(\mathrm{p}=0.007)$, pray and fasting $(\mathrm{p}<0.001)$ with mean total score of spiritual health.

Conclusion: In the dimensions of the ethical system and lifestyle, the mean score of students was lower than the other dimensions, which could be somewhat alarming. It is recommended that the cultural planners of the universities Pay close attention and apply appropriate training.
\end{abstract}

Keywords: Spiritual health, Student, Religious, Moral, Iran

How to cite this article : Sayyadi M, Sayyad S, Vahabi A, Vahabi B, Noori B, Amani M. Evaluation of spiritual health level and its related factors in the students of Sanandaj Universities, 2015. Shenakht Journal of Psychology and Psychiatry. 2019; 6 (1): 1-10.

URL :http://shenakht .muk.ac.ir/article-1-475-fa.pdf

Copyright (C) 2018 the Author (s). Published by Kurdistan University of Medical Sciences. This is an open access article distributed under the terms of the Creative Commons Attribution-Non Commercial License 4.0 (CCBY-NC), where it is permissible to download, share, remix, transform, and buildup the work provided it is properly cited. The work cannot be used commercially without permission from the journal. 


\title{
بررسى سطح سلامت معنوى و عوامل مرتبط با آن در دانشجويان \\ دانشكاههاى شهر سندج در سال ماى
}

\author{
مهناز صيادى'، سيروان صياد'، احمد وهابى '، بشرى وهابى'، بيزن نورى'، منا امانى' \\ ا. ا.كميته تحقيقات دانشجويى، دانشكاه علوم يزشكى كردستان، سنندج، ايران.

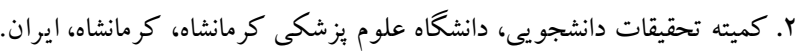

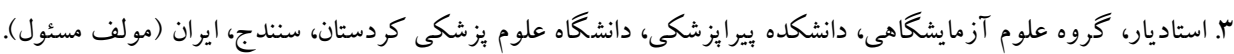 \\ vahabiahmad@gmail.com : يميل \\ ؟. استاديار، مر كز تحقيقات عوامل اجتماعى مؤثر بر سلامت، يُوهشكده توسعه سلامت، دانشكاه علوم يز شكى كردستان، سندج، اير ان.

مقدمه: معنويت بهعنوان مهم ترين بعد وجودى انسان است كه به عنوان نيرويى قوى در مركز زندگى بيشتر از يككسوم مردم دنيا

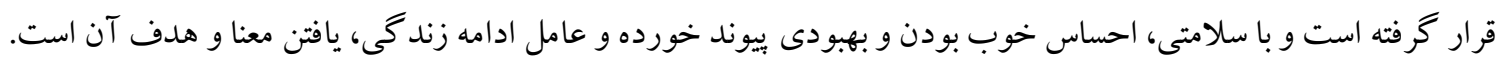
هدف: اين مطالعه با هدف تعيين سطح سلامت معنوى و عوامل مرتبط با آن در دانشجويان دانشگاههاى شهر سندج در سال IFqF انجام گرديد.

روش: اين مطالعه يكك بررسى مقطعى بود كه در بين دانشجويان دانشگاههاى كردستان، آزاد اسلامى ستندج و علوم بز شكى

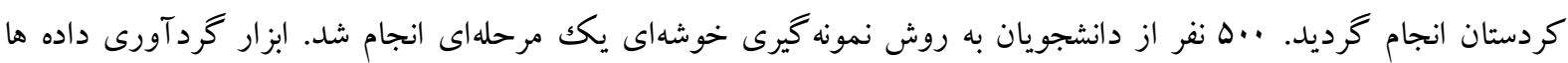

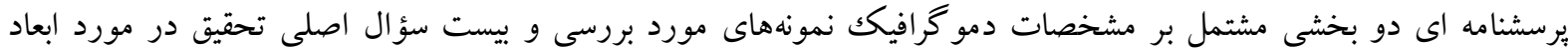

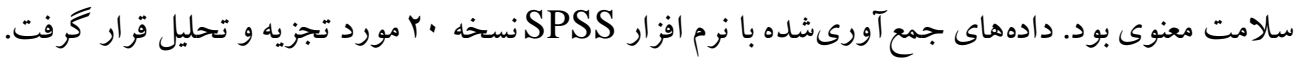
يافته ها: ميانكين نمره كسب شده بعد نظام اعتقادى، نظام فكرى، نظام اخلاقى، نظام سبك زند گى سلامت معنوى به ترتيب برابر با 年

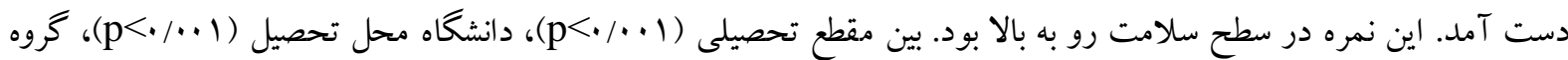

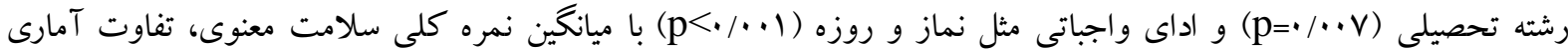

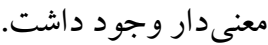
نتيجه كيرى: در ابعاد نظام اخلاقى و سبك زندگى، نمره ميانكين دانشجويان نسبت به ساير ابعاد كمتر بود كه اين مىتواند مقدارى نكر انكنده باشد. توصيه مىشود برنامه ريزان فرهنگى دانشخاههاى مورد بررسى به اين مهم توجه داشته باشند. كليدوازهها: سلامت معنوى، دانشجو، دين دارى، اخلاق، ايران 
مختلف وجود و داشتن انتخابهاى مختلف دانست

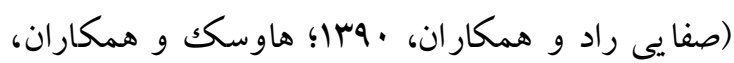

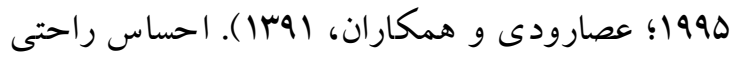
و قدرت به وجود آمده از اعتقادات دينى مى تواند در همراتر سلامتى و احساس خوب بودن انسان نقش داشته باشد. اعمال دينى اكر خه ممكن است سبب بهبودى بيمارى

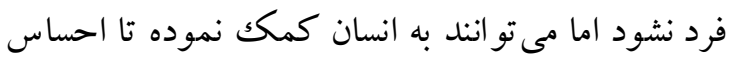
خوبى داشته باشد و از برخى مشكلات بيمارى به

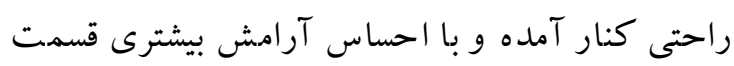

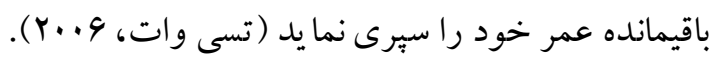
در صورت ارتباط معنوى با قدرت بى كران، اطمينانى در انسان به وجود مى آيد كه نيرويى قوى هميشه او را

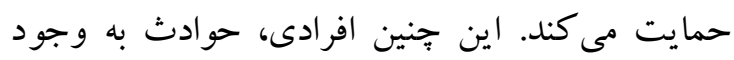

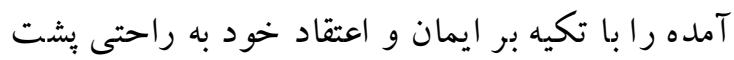

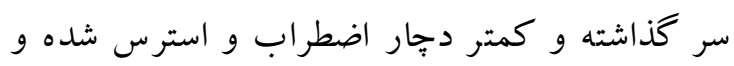
انتظار آنها از آينده خوشبينانهتر و اميدوارانهتر است

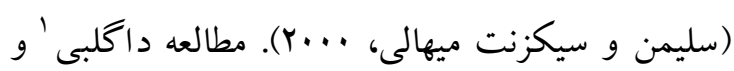

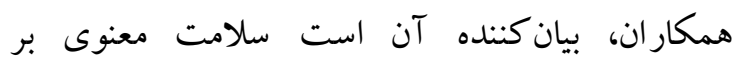
رضايت شغلى تأثير مثبت داشته است (داقلبى و ونال

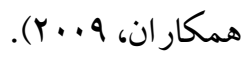
مطالعه انجام شده در دانشگاه علوم يزشكى اردبيل نشان

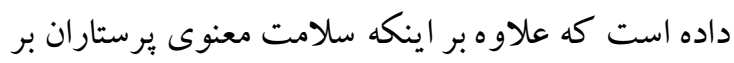

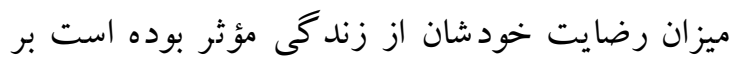
ميزان رضايت بيمار ان از مراقبتهاى برستار ان نيز تأثير داشته است (فاطمى و همكاران، •وبا). در مطالعه ديخرى كه در بين دانشجويان مامايى انجام شده است، مشخص شده است كه 9FN \% T آنها از سلامت معنوى در حد متوسط برخوردار بوده و ميانگين كلى امتياز سلامت معنوى آنها،

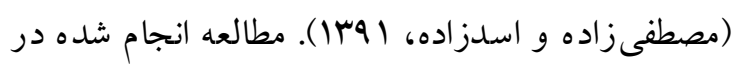
بين دانشجويان كارشناسى ارشد يرستارى تايوان نشان

${ }^{1}$ Duggleby
انسان مو جودى است كه در آفرينش آن ابعاد مختلفى از جمله جسمى، روانى، اجتماعى و معنوى وجود دارند. بعد معنوى اين مو جود (انسان) سبب ارتقاى سلامت معنوى او شده و باعث هماهنكى در بين ساير

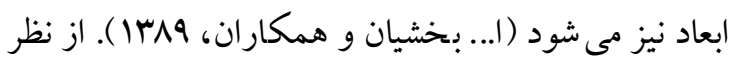
يزشكى، جسم انسان با روح او در ارتباطى تنگًاتنگك

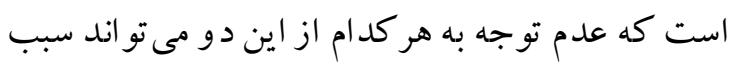
صدمات جبران نايذيرى در انسان شود (فراهانى نيا و ودئ همكاران، وجودى انسان است كه به عنوان نيرويى قوى در مركز زندكى بيشتر از يك سوم مردم دنيا قرار گرفته است و و ونئ با سلامتى، احساس خوب بودن و بهبودى بيوند خورده

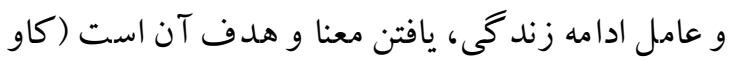

$$
\text { انديش و همكاران، r... (Y). }
$$

سلامت معنوى به حالتى از بودن، واكنش احساسات

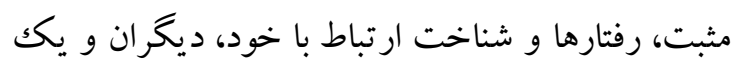
نيروى ماورايى و فطرى گفته مى شود كه فرد متمايل به احساس هويت، كمال، رضايتمندى، لذت، خرسندى،

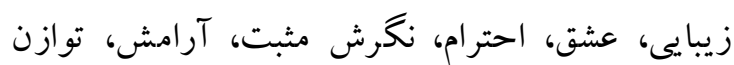

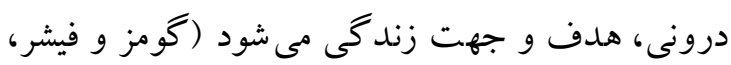

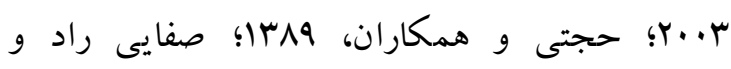

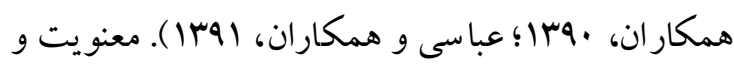
اعتقاد به خدا جزو مهمترين ابعاد وجودى انسان است كه هيج وقت انسان از آن بى نياز نبوده و بدون اين بن بندان اعتقاد زند گى براى بشر بى معنى تلقى مى شود (بهر و ونى

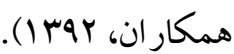
سلامت معنوى داراى دو بعد سلامت مذهبى و سلامت وجودى است. سلامت مذهبى بيانگر ارتباط با خدا و

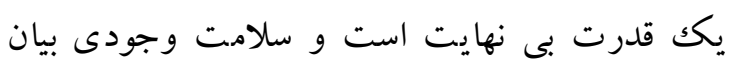
كننده ارتباط ما با ديگران، محيط و با درون خودمان

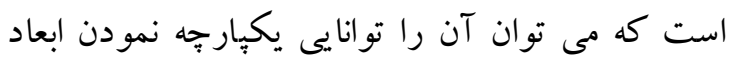


روش

اين مطالعه از نوع مقطعى بود كه در سال عqrا اجرا كرديد. جامعه مورد بررسى در اين مطالعه دانشجويان دانشگاههاى علوم يزشكى كردستان، كردستان و آزاد اسلامى سنندج بودند. معيار ورود: دانشجوى يكى از دانشگاههاى علوم بزشكى كردستان، كردستان و آزاد اسلامى سنندج بودن، تمايل به شركت در مطالعه و

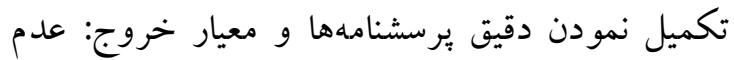

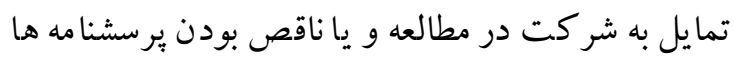
و فارغالتحصيل شدن از دانشگاه به عنوان معيارهاى خروج از مطالعه منظور شدند. جهت به دست آوردن حجم نمونه مورد نياز براى برآورد سلامت معنوى

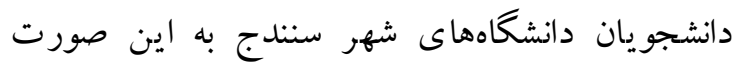
عمل گرديد: از مطالعات مشابه قبلى مقدار انحراف

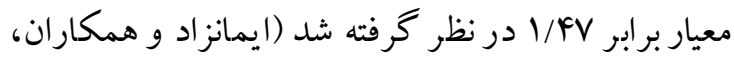
سوسا). مقدار دقت نيز برابر با ها, • انحراف معيار در

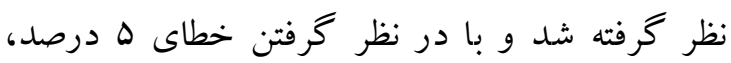
حجم نمونه مورد نياز بر ابر با سF نو نفر به دست آمد و درر

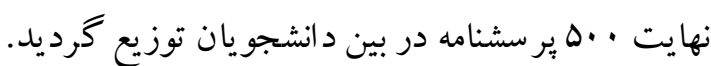
نمونه گيرى به صورت خو شه اى يكك مرحلهاى انجام شد. هر دانشگاه يك خوشه در نظر كرفته شد. متناسب با حجم هر دانشكاه دانشجويان براى تكميل يرسشنامه

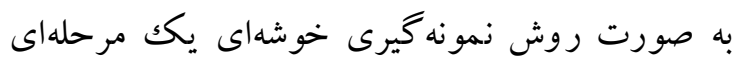

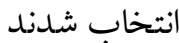
براى انجام اين يُزوهش از يرسشنامه بكار گرفته شدهدر

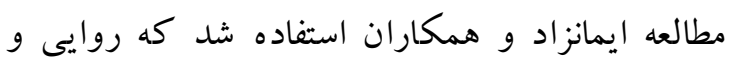
پايايى آن را تأييد نموده و مقدار آلفاى كرونباخ آن راد

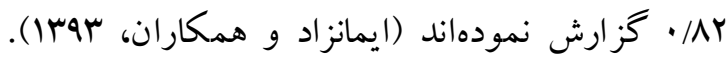
اين برسشنامه مشتمل بر دو نوع سؤال است. در قسمت اول آن سؤالاتى مانند سن، جنسيت، مقطع تحصيلى،

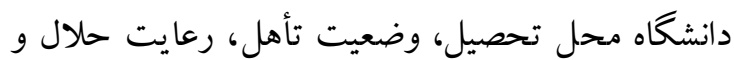

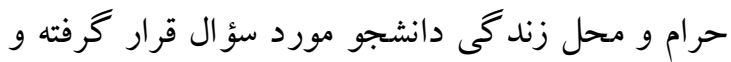

داده است كه سلامت معنوى آنها در حد متوسط بوده

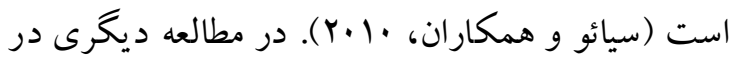
بين دانشجويان علامه طباطبايى تهران مشخص شده است كه ارتباط مستقيمى بين سلامت معنوى و سلامت روانى دانشجويان مورد بررسى وجود داشته است

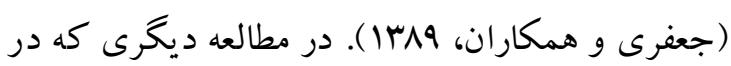
بين دانشجويان سنگًايورى انجام شده است، آكاهى آنها از سلامت معنوى در حد بالا و زياد بر آورد شده

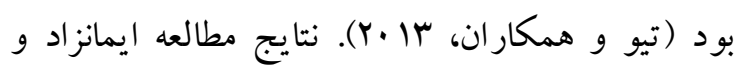
همكار ان آنها نشان داده است كه نمره سلامت معنوى rه/ نمونهاى مورد بررسى، در سطح متوسط رو به بالا

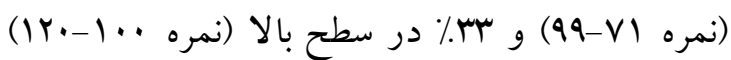
بوده است (ايمانزاد و همكاران، سوسا). در مطالعه ديخرى كه توسط رحيمى و همكار ان انجام شده بود بيانكر آن است كه نمره سلامت معنوى دانشجويان

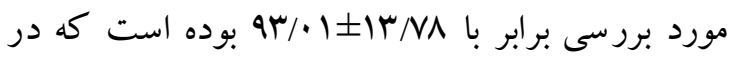

حد متوسط بوده است (رحيمى و همكار ان، سوس 1).

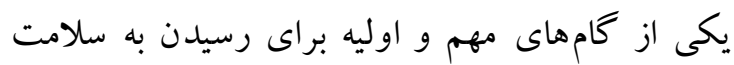

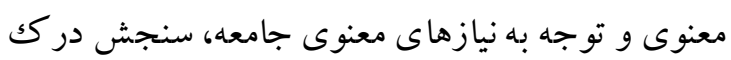

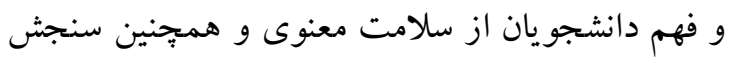
ميزان آن در بين دانشجويان است. نظر به اينكه اكثر مطالعات انجام شده در مورد سلامت معنوى در بين بيماران و يا برسنل مراقبت كننده از آنها (يرستار ان) انجامشده است و كمتر مطالعهاى در بين دانشجويان

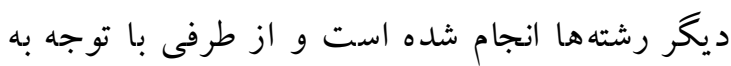

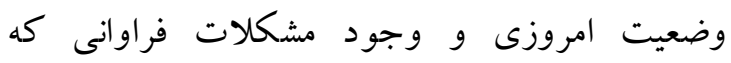
دانشجويان با آنها روبرو هستند سنجش سلامت معنوى ورى آنها يكك نياز است؛ لذا مطالعه حاضر با هدف تعيين

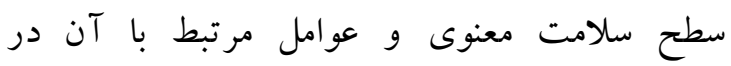

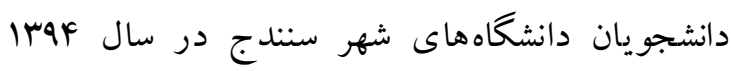
طراحى و انجام گرديد. 


\section{يافتهها}

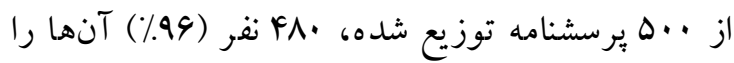
تكميل نموده و بر گرد انند. ميانگين سن نمونه هاى مورد

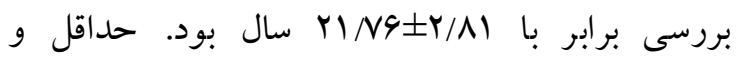
حداكثر سن آنها به ترتيب برابر با ها و و ها سال بود.

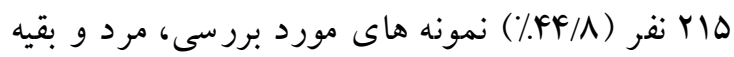

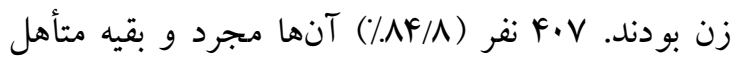

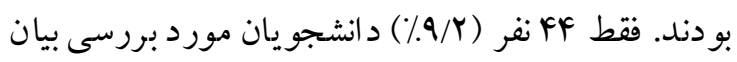
كرده بودند كه محرمات را رعايت نمى كنند و بقيه

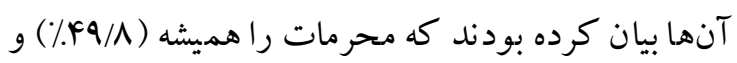

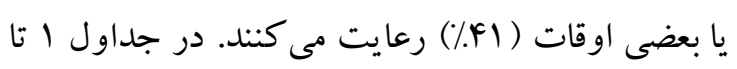

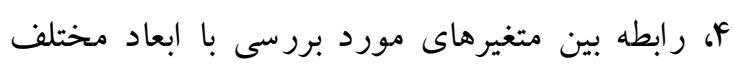
سلامت معنوى نشان داده شده است. ميانخين نمره كسب شده بعد نظام اعتقادى، نظام فكرى،

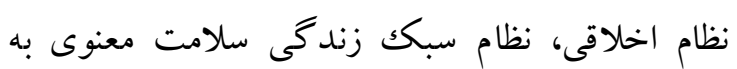

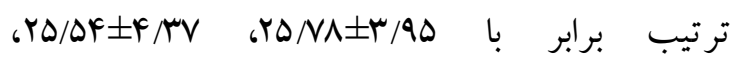

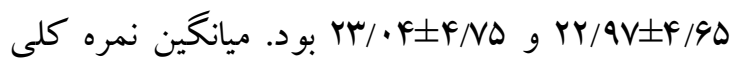
سلامت معنوى برابر با و $99 / \%$ به دست آمد.

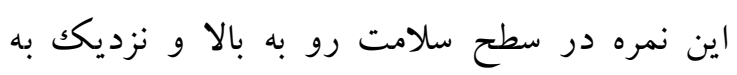

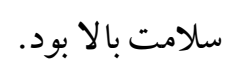

در قسمت دوم آن ·r سؤال اصلى تحقيق در مورد سلامت معنوى است كه در معيار 9 درجه اى ليكرت از

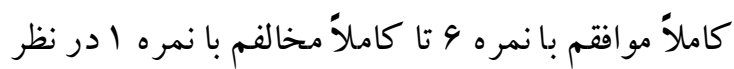

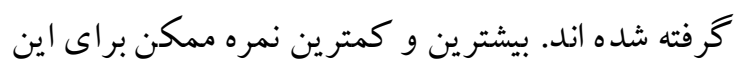

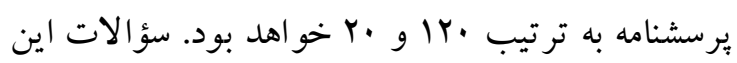
برسشنامه مشتمل بر F حيطه است كه شامل حيطه نظام اعتقادى، نظام فكرى (انديشه)، نظام اخلاقى (ارزش ها) و سبك زند گى است. در هر حيطه هأؤال وجود د دارد. در زمان جمع آورى داده ها بر اساس سهم هر دانشگًاه،

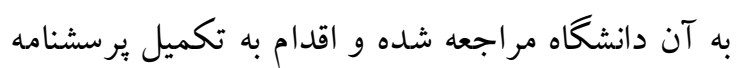

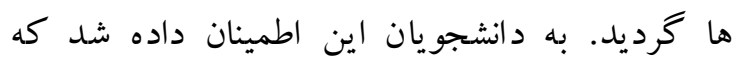

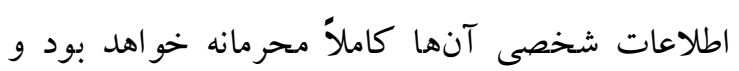
آنها نيازى به نوشتن نام خود نداشتند.

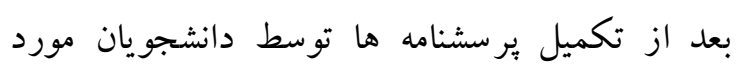
بررسى، داده هاى موجود در بر سشنامه وارد نرم افزار SPSS r.

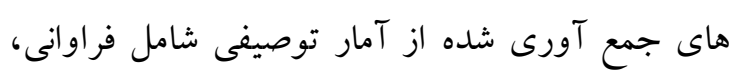
ميانگين و انحراف معيار و آمار تحليلى از قبيل آزمون

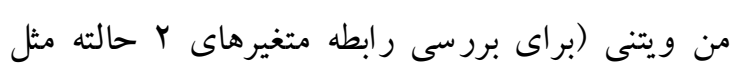

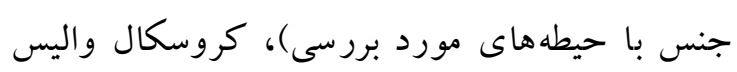

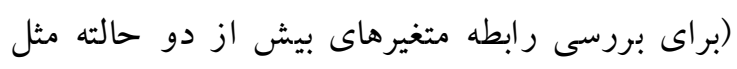

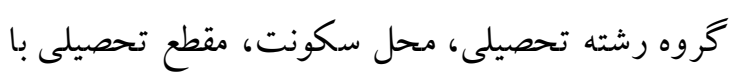
حيطه هاى مورد بررسى) استفاده شد.

\begin{tabular}{|c|c|c|c|c|c|c|}
\hline$p$ & $\mathbf{Z}$ & دختران & يسران & انحراف & ميانكين & حيطه هاى مورد \\
\hline$\cdot / \cdots p$ & $-Y / \wedge 9$ & $\Delta / r \mu \pm \cdot / N a$ & $\Delta / .9 \pm \cdot N \Lambda$ & $\cdot / \mathrm{Na}$ & $\Delta / 19$ & نظام اعتقادى \\
\hline$\cdot / M r$ & $-1 / 09$ & $F / 9 \Delta \pm \cdot / M$ & $F / \wedge \Delta \pm \cdot / \wedge \varphi$ & $\cdot / \mathrm{AV}$ & $r / 91$ & نظام فكر ى \\
\hline$\cdot N r$ & $-\cdot / 49$ & $F / \Delta q \pm \cdot / q \Lambda$ & $F / 9 \cdot \pm \cdot / \Lambda 9$ & - & $F / \Delta q$ & نظام اخلاقى \\
\hline$\cdot N$ & $-\cdot / \mu$ & $r / 9 Y \pm \cdot / 99$ & $F / \Delta q \pm \cdot / q F$ & $\cdot / 90$ & $f(9)$ & سبكى زند \\
\hline$\cdot / \cdot V$ & $-I / A Y$ & $F / \wedge \Delta \pm \cdot / N \wedge$ & $F / N \wedge \pm \cdot / 99$ & - Na & $F / A r$ & نمره كل \\
\hline
\end{tabular}


دانشجويان پسر بود ولى فقط در بعد نظام اعتقادى، در همه ابعاد مورد بررسى، بين نمره سلامت معنوى

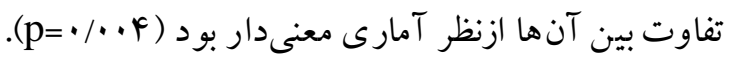
دانشجويان دختر و يِر تفاوت وجود داشت. نمره سلامت معنوى دانشجويان دختر بالاتر و بيشتر از

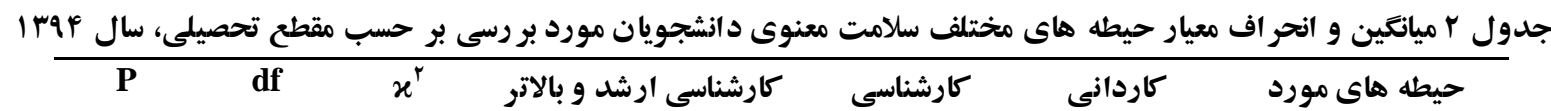

\begin{tabular}{|c|c|c|c|c|c|c|}
\hline$\cdot / M$ & r & $\cdot / r \Delta$ & $\Delta / r q \pm \cdot / \Delta r$ & $\Delta /|f \pm \cdot / \Lambda|$ & $\Delta / / \Delta \pm \cdot / N \Delta$ & نظام اعتقادى \\
\hline .1 .4 & r & 91.9 & $\Delta / \mathrm{TV} \pm \cdot / \Delta \Lambda$ & $F / M \pm \cdot / \Lambda q$ & $r / \wedge r \pm \cdot / q$. & نظام فكرى \\
\hline$<\bullet / \cdot \cdot 1$ & r & $r r / q \Lambda$ & $\Delta / F \cdot \pm \cdot|\Delta|$ & $r / \Delta r \pm \cdot / q r$ & $F / \Delta \Delta \pm \cdot / \Lambda F$ & نظام اخلاقى \\
\hline$<\cdot / \cdot \cdot 1$ & r & $r I / M F$ & $\Delta / r \cdot \pm \cdot / \Delta V$ & $\varphi / \Delta \Delta \pm \cdot / Q \varphi$ & $\uparrow / \wedge \Delta \pm \cdot / ৭ ৭$ & سبكى زند \\
\hline$<\bullet / \cdot \cdot 1$ & r & $19 / 91$ & $\Delta / r q \pm \cdot / \kappa r$ & $F / W \pm \cdot N \Delta$ & $F / \wedge \Delta \pm \cdot / N G$ & نمره كل \\
\hline
\end{tabular}

بوده و نمره بيشترى را كسب كرده بودند. بهجز در بعد اعتقادى سلامت معنوى، در ابعاد ديكر سلامت معنوى تفاوت نمره دانشجويان مقاطع تحصيلى از نظر آمارى معنى دار بود ( ه • (p)
در همه ابعاد مورد بررسى سلامت معنوى، بين دانشجويان مقاطع مختلف تحصيلى، تفاوت وجود داشت. در همه ابعاد سلامت معنوى، دانشجويان كارشناسى ارشد و بالاتر از وضعيت بهترى برخوردار

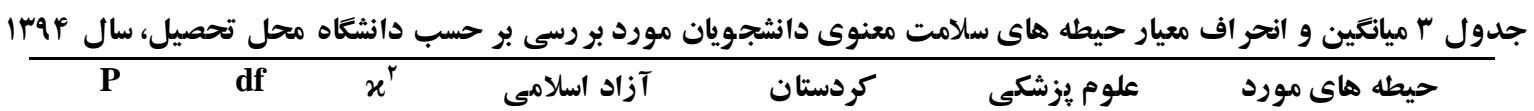

\begin{tabular}{|c|c|c|c|c|c|c|}
\hline & & & & & & بروسى \\
\hline.$/ . r$ & r & $V / \cdot 9$ & $\Delta / \Lambda \cdot \pm \cdot / \vee q$ & $\Delta / 1 I \pm \cdot / \Lambda r$ & $\Delta / r \Delta \pm \cdot N$ & نظام اعتقادى \\
\hline .1 .4 & r & $4 / 4 \varphi$ & $F / \wedge \Delta \pm \cdot / Q V$ & $F / \Lambda 9 \pm \cdot / \Lambda)$ & $\Delta / M \pm \cdot M$ & نظام فكرى \\
\hline$\cdot 1 \cdot \cdot 1$ & r & Ir/vo & $F / 9 \Lambda \pm 1 / \cdot V$ & $F / F F \pm \cdot / A r$ & $F / W \pm \cdot N q$ & نظام اخلاقى \\
\hline$<\bullet / \cdot 1$ & r & $r \cdot r \cdot$ & $f / 9 \mathrm{~V} \pm 1 / .9$ & $\mathrm{~F} / \mathrm{Kr} \pm \cdot / \wedge q$ & $F / \wedge 9 \pm \cdot / 9 \Lambda$ & سبكك زند \\
\hline$<\cdot / \cdot \cdot 1$ & r & $\mathrm{IV} / \cdot \mathrm{V}$ & $F / A r \pm \cdot / M$ & $F / N I \pm \cdot / 9 \mathrm{~V}$ & $\Delta / \cdot Y \pm \cdot / \Delta \Delta$ & نمره كل \\
\hline
\end{tabular}

دانشجو يان دانشگاه علوم يزشكى كردستان از وضعيت بهترى برخوردار بوده و نمره بيشترى را كسب كرده بودند.
در همه ابعاد مورد بررسى سلامت معنوى، نمره دانشجويان سه دانشخاه مورد بررسى، تفاوت داشت و اين تفاوت در همه ابعاد سلامت معنوى از نظر آمارى معنى دار بود ( ه •/p). در همه ابعاد سلامت معنوى،

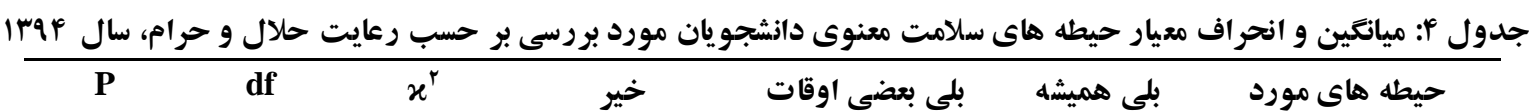

\begin{tabular}{|c|c|c|c|c|c|c|}
\hline$<1$ & $r$ & ryar & $x / a x+1, y$ & $\Delta, a+, 0$ & M & 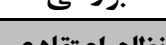 \\
\hline & 1 & (1) & $1 / 7=1 / 1$ & $\omega / \cdot T \perp \cdot / v i$ & $0 / 111.0 / 74$ & لطام أمشعادى \\
\hline$<\cdot / \cdots)$ & r & rV/r. & $F / T V \pm l / l$. & $\mathrm{F} / \Lambda \mathrm{Y} \pm \cdot / \wedge q$ & $\Delta / \cdot ৭ \pm \cdot /{ }^{f}$ & نظام فكرى \\
\hline
\end{tabular}




\begin{tabular}{|c|c|c|c|c|c|c|}
\hline.$/ \cdots r$ & $r$ & $\mid r / N \wedge$ & $f / .9 \pm 1 / .9$ & $F / \Delta q \pm \cdot / q V$ & $r / 99 \pm \cdot / \wedge r$ & نظام اخلاقى \\
\hline$\cdot / \cdot r$ & r & $1 r / \Delta 9$ & $\varphi / \cdot \Delta \pm 1 / 11$ & $f / \Delta q \pm 1 / \cdot 1$ & $F / v \Delta \pm \cdot / \Lambda \mid$ & سبكى زند كى \\
\hline$<\cdot / \cdot \cdot 1$ & r & rI/qr & $F / r \Delta \pm 1$ & $F / N G \pm \cdot N \Delta$ & $\mathcal{F} / q \mathrm{~V} \pm \cdot / q \mathrm{q}$ & نمره كل \\
\hline
\end{tabular}

مطالعه عصاررودى و همكاران ( •هr|)، يزدى مقدم و همكاران (IMMM) نيز بيان شده است كه بين جنس هنس نمونهاى مورد برر سى و نمره كلى سلامت معنوى،

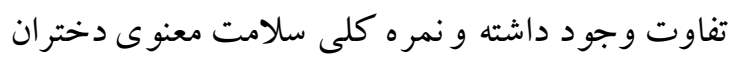

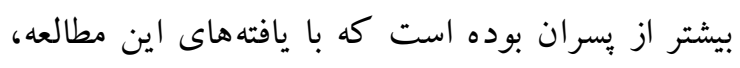

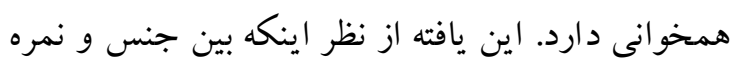
كلى سلامت معنوى رابطه آمارى معنى دارى ندارد با نيا

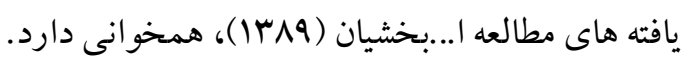
نتايج اين مطالعه نشان داد كه بين محل اسكان دانشجويان (همراه خانواده و دور از خانواده) و نمره

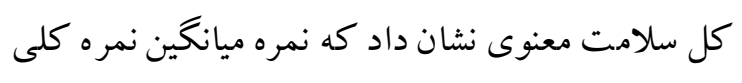
سلامت معنوى دانشجويانى كه همراه خانو اده زندكى مى كنند با آنهايى كه دور از خانواده در منزل مجردى دمى دمانى

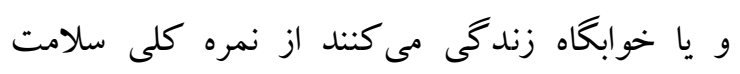
معنوى بالاترى برخوردار بودند. نمره سلامت معنوى

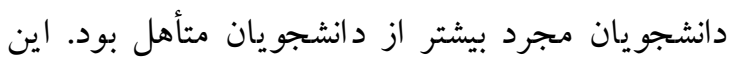

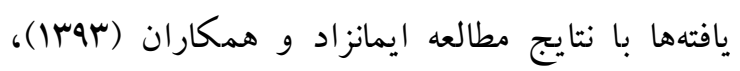
همخوانى دارد. يكى از دلايل مهم اين تفاوت ممكن

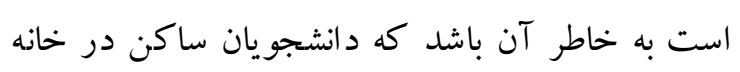

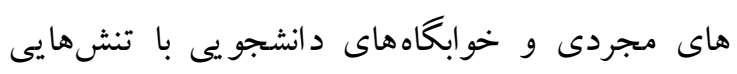

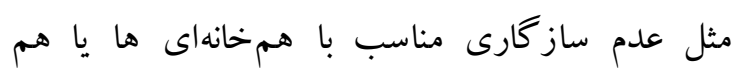

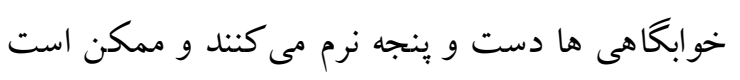
اين ناساز كارىها بر روحيه آنها تأثير منفى كذاشته دئه باشد و نمره كلى سلامت معنوى آنها را تحت الشعاع

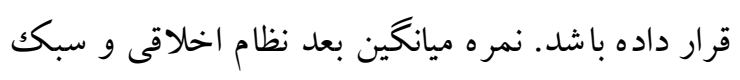

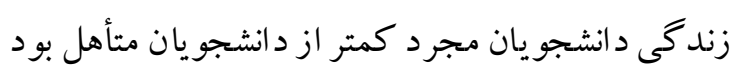
ولى در ابعاد ديخر نمره ميانگين دانشجويان مجرد بالاتر

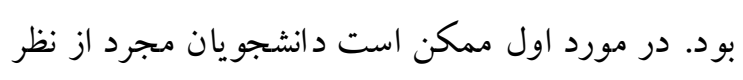

در همه ابعاد سلامت معنوى، نمره دانشجويانى كه هميشه حلال و حرام را رعايت مى كنند بالاتر از بقيه

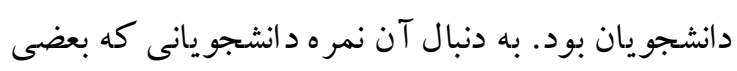
اوقات حلال و حرام را رعايت مى كنند، قرار داشت.

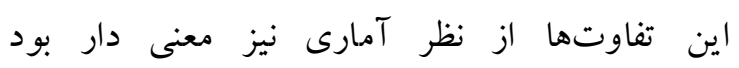
. $(\mathrm{p}<\cdot / \cdot \Delta)$

\section{بحث و نتيجه كيرى}

اين مطالعه كه به بررسى سطح سلامت معنوى ونيرى و عوامل

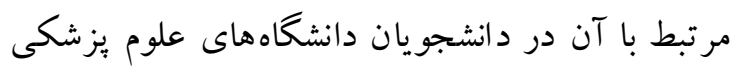
كردستان، آزاد اسلامى سندج و ود دانشگاه كردستان يرداخته است بيانكر آن است كه سلامت معنوى دانشجو يان مورد بررسى در حد متوسط رو به بالا است و اين نشان دهنده آن است كه سطح سلامت معنوى آنها مطلوب و مناسب است. يافته هاى اين مطالعه نشان داد كه بين سلامت معنوى د انشجويان دختر و يسر تفاوت وجو د داشت و نمره سلامت معنوى د انشجويان

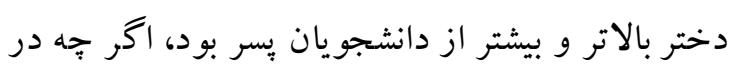

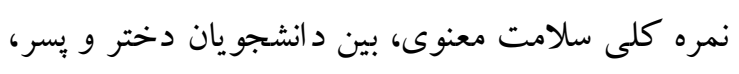
تفاوت آمارى معنى دارى مشاهده نشد ولى در بعد نظام

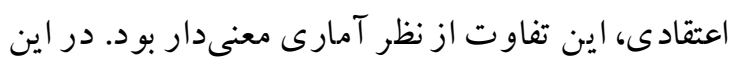

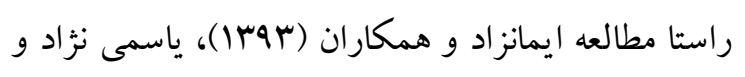

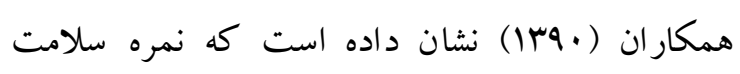

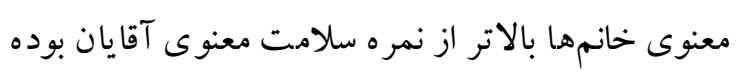

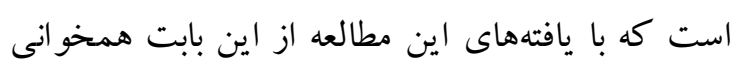

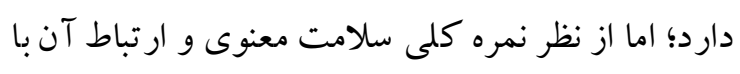
جنسيت دانشجويان، يافتهاى اين مطالعه با يافتههاى دئى

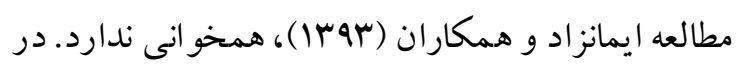


موارد را انجام نمىدادند از سطح سلامت معنوى بالاترى در همه ابعاد سلامت معنوى بر خوردار بو دند. در زمينه نحوه آموزش بايستى به خاطر داشته باشيم؛ جون معنويت كاملاًً شخصى و ذهنى است، لازم است در كلاس درس، محيط آموزشى مناسب فراهم شده و دانشجويان به اين باور برسند كه محيط كلاس امنيت كامل را داشته و در صورتى كه اعتقادات خود را بيان نمايند براى آنها مشكلى بيش نخواهد آمد، به راحتى اعتقادات معنوى خود را بيان مى كنند. ارتباط مستقيم و مهمى بين معنويت و بهبودى از بيمارى وجود دارد. در اين راستا، مطالعه فهرينگك و همكاران ا كه سلامت معنوى بيماران سرطانى (199V) اندازه كيرى كرده بودن به اين نتيجه رسيده بودند كه بيماران داراى مذهب درونى قوى تر، زودتر و سريع تر از بيمارى خود خلاص شده بودند.

نظر به اينكه ميانكين نمره سلامت معنوى دانشجويان دانشخاه علوم يزشكى كردستان در اين مطالعه از ميانگين نمره سلامت معنوى دانشجويان دانشخاههاى مورد بررسى ديخر بالاتر بود مى توان جنين بيان نمود كه اين كروه از دانشجويان كه كار مراقبت از بيماران را بر عهده دارند و ارائهدهند گان خدمات سلامت هستند، از سلامت معنوى خوبى بر خوردار هستند و با اين سطح بالاى سلامت معنوى مى تو انند خدمات خود را بهتر ارائه نمايند. از نقاط قوت اين مطالعه اين است كه مطالعه در بين سه دانشخاه اصلى شهر سنتدج انجام شده است و و دانشجو يان رشتههاى مختلف در مقاطع مختلف و سنين متفاوت در آن شركت داشتهاند. از محدوديتهاى اين مطالعه مىتوان به حجم كم آن اشاره نمود كه در هر دانشگاه، تعداد كمى از دانشجويان، مورد بررسى قرار كرفته اند. همجينين اين مطالعه يكك بررسى خود
اخلاقى و سبك زندكى بسيار خود را مقيد نكرده باشند و دانشجويان متأهل به خاطر وجود شريك زندگى، بيشتر احساس مسئوليت كرده و خود را مقيد به رعايت امورات اخلاقى و زندگى مشتر ك بدانند. در مورد ساير ابعاد، نيز مى توان اين گونه اظهارنظر كرد كه مجردها نسبت به متأهلين از نظر فكرى و اعتقادى، احساس استقلال بيشترى كرده و درگيرىهاى فكرى و اعتقادى كمترى دارند و ممكن است به اين خاطر از نمره بالاترى بر خوردار باشند. يافته هاى اين مطالعه نشان داد كه ميانخين نمره كلى سلامت معنوى گروههاى سنى ·r سال و بالاتر، تفاوتى با هم نداشت و فقط در گروه سنى 11 تا 19 سالهها، ميانگين كلى نمره سلامت معنوى كمى پايينتر از ساير كروهها بود. اين يافتها با نتايج مطالعه ايمانزاد و همكار ان (سوس ا ) از اين بابت همخو انى ندارد. در اين مطالعه نمره سلامت معنوى دانشجويان كروه يزشكى از ساير دانشجويان بالاتر بود. در مطالعه ايمانزاد و همكار ان نيز اشاره شده بود كه نمره سلامت معنوى دانشجويان برستارى از ساير دانشجويان بالاتر بوده است (ايمانزاد و همكاران، سوس|). سيائو و همكاران

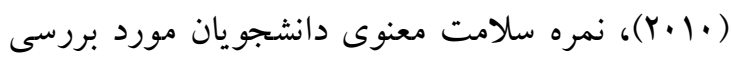
را متوسط اعلام كرده اند. همجينين در مطالعه صفايى راد و همكاران (.9 (I)، نمره سلامت معنوى دانشجويان مورد بررسى در سطح خوب كزارش شده است كه اين يافته ها با نتايج اين مطالعه، همخوانى

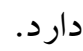
نتايج اين مطالعه نشان داد كه سطح سلامت معنوى افر اد ارتباط مستقيم و معنى دار قو يى با نماز خو اندن، روزه كرفتن و رعايت حلال و حرام توسط افراد رادارد و در مورد هر سه مورد اخير، سلامت معنوى دانشجو يانى كه به آنها جواب بلمى داده بودند نسبت به آنهايى كه اين 
multiple sckerosis patients. Zahedan Journal of Research in Medical Sciences. 2010; 12(3):29-33. [Persian]

Asarrodi A, Golafshany A, Akabery A. Relationship of spiritual health and life quality of nurses. Joumal of North Khorasan University of Medical Scienc. 2011; 3(4):81-88. [Persian]

Behere PB, Das A, Yadav R, Behere AP. Religion and mental health. Indian Journal of Psychiatry. 2013; 55(suppl2): 187-194.

Cavendish R, Konecny L, Mitzeliotis C, RUSSO D, Luke BK, Lanza M, et al Spiritual care activities of nurses using nursing interventinons classification (NIC) labels. International Journal of Nursing Terminologies and Classifications. 2003; 14(4): 113-124.

Duggleby W, Cooper D, Penz K. Hope, self-efficacy, spiritual well-being and job satisfaction. Joumal Of Advanced Nursing. 2009; 65(11):2376-2385.

Farahaninia M, Abbasi M, Givari A, Haghani H. Nursing students' spiritual well-being and their perspectives towards spirituality and spiritual care perspectives. Iran Journal of Nursing. 2006; 18(44): 7-14. [Persian]

Fatemi M, Nazari R, Safavi M, Naeini MK, Savadpour MT. Relationship between spirituality and nurses on patient satisfaction with nursing care. The Iranian Journal of Medical Ethics. 2011; 5(17): 141-159. [Persian]

Fehring RJ, Miller JF, Shaw C, editors. Spiritual wellbeing, religiosity, hope, depression, and other mood states in elderly people coping with cancer. Oncology Nursing Forum 1997; 24(4):663-671.

Gomez R, Fisher JW. Domains of spiritual welt being and development and validation of the spiritual well-being questionnaire. Personality and Individual Differences. 2003;35(8): 1975-1991.

Hawks SR, Hull ML, Thalman RL, Richins PM. Review of spiritual health: definition, role, and intervention strategies in health promotion. American Journal of Health Promotion. 1995;9(5):371-378.

Hojjati H, Motlagh M., Nouri F., Shirifnia S. H, Mohammadnejad E, Heydari B. Relationship between different dimensions

$$
\begin{aligned}
& \text { كزارشى است و ممكن است برخى از دانشجويان با } \\
& \text { دقت كافى برسشنامهها را تكميل نكرده باشند. } \\
& \text { نتايج مطالعه نشان داد كه اكثر دانشجويان مورد بررسى } \\
& \text { از سطح سلامت معنوى بسيار خوبى برخوردار هستند و } \\
& \text { اين جاى بسيار خوشحالى است اما در موارد نظام } \\
& \text { اخلاقى و سبكك زندگى، در اكثر نمونهاى مورد } \\
& \text { بررسى، اين سطح به نسبت نظام اعتقادى كمى بايين تر } \\
& \text { است و اين مى تواند زنگك خطى باشد تا بـ برنامه ريزان }
\end{aligned}
$$

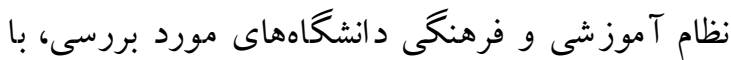

$$
\begin{aligned}
& \text { برنامهريزى دقيق تر و اجراى برنامه هاى مناسب } \\
& \text { فرهنگ و فوق برنامهاى، اين دو بعد سلامت معنوى را } \\
& \text { در بين دانشجو يان ارتقا بخشند. }
\end{aligned}
$$

$$
\text { سياسگز ارى }
$$

نويسند كان اين مقاله بر خود لازئ ميدائ دانند از همه

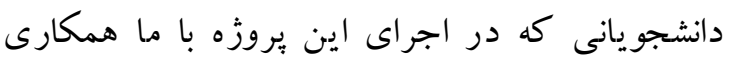

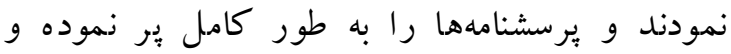

تحويل دادند، تشكر و قدردانى نمايند. همجِنين از

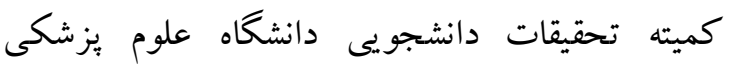
كردستان به خاطر همكارى در تصويب اين طرح و

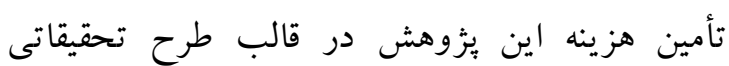
دانشجويى، تشكر و قدردانى مى گردد. هزينه اجراى اين بزٔوهش توسط معاونت تحقيقات و فناورى د انشگاه علو ميزشكى كردستان تأمين گرديده است.

\section{References}

Abbasi M, Ażzi F, Shamsi A, Naseri M, Akbari M. The definition of the concepts and operations of spiritual health: a methodological study. The Iranian Journal of Medical Ethics. 2012; 6(20): 11-44. [Persian]

Allahbakhshian M, Jaffarpour M, Parvizy S, Haghani H. A survey on relationship between spiritual well-being and quality of life in 
of prayer and spiritual health of patients treated with hemodialysis. IJCCN. 2010; 2(4): 149-152.[Persian]

Hsiao YC, Chiang HY, Chien LY. An exploration of the status of spiritual health among nursing students in Taiwan. Nurse Education Today. 2010;30(5):386-392.

Imanzad M, Tavan H, Taghinejad H, Mousavi Moghadam R, Sayehmire K. Spiritual health among nursing and midwifery students at Kerman University of Medical Sciences. Joumal of Shahid BeheshtiSchool of Nursing \& Midwifery. 2014; 23(80): 2533. [Persian]

Jafari E, Dehshiri GR, Eskandari H, Najafi M, Heshmati R, Hoseinifar J. Spiritual wellbeing and mental health in university students. Procedia Social and Behavioral Sciences. 2010; 5: 1477-1481.

Mostafazadeh F, Asadzadeh F. Spiritual health of midwifery students. Iranian Joumal of Health \& Care. 2012; 14(1, 2): 55-60. [Persian]

Osarrodi A, Golafshani A, Akaberi S. Relationship between spiritual wellbeing and quality of life in nurses. 2012;3(4):79-88. [Persian]
Rahimi N, Nouhi E, Nakhaee N. Spiritual health among nursing and midwifery students at Kerman University of Medical Sciences. Hayat. 2014; 19(4): 74-81. [Persian]

Safee Rad I, Karimi L, ShomoossiN, Ahmadi Tahor $\mathrm{M}$. The relationship between spiritual wellbeing and mental health of university students. 2011;17(4):274-280. [Persian]

Seligman M, Csikszentmihalyi M. Positive psychology: An introduction American Psychologist. 2000;55(1):5-14.

Tiew LH, Creedy DK, Chan MF. Student nurses' perspectives of spirituality and spiritual care. Nurse Education Today. 2013;33:574-579.

Tsevat J. Spinituality/religion and quality of life in patients with HIV/AIDS. Journal of General InternalMedicine. 2006;21(Supp15):S1-S2.

YazdiMoghaddamH, EstajiZ, Heidari. Study of the quality of life of nurses in Sabzevar hospitals in 2005-2006. Quarterly JoumalofSabzevar University of Medical Sciences. 2009; 16(1):50-55. [Persian]

Yseminejad P, Golmohammadian M, Yosefi N. Study the relationship of spiritual health and job involvement in academic staff. Quarterly Joumal of Career \& Organizational Counseling. 2011;3(8): 110-125. [Persian] 